\title{
Alternations of Liver Pathophysiology in Experimental Hepatic Failure Treated by Two Forms of Plasma Purification Procedure
}

\author{
Kiyoaki Ouchi, Kenji Okabe, Yoshiniro Asanuma, \\ Kenji Koyama and Toshio Sato \\ Department of Surgery, Tohoku University Schoool of \\ Medicine, Sendai 980
}

Ouchi, K., Okabe, K., Asamura, Y., Koyama, K. and Sato, T. Alternations of Liver Pathophysiology in Experimental Hepatic Failure Treated by Two Forms of Plasma Purification Procedure Tohoku J. exp. Med., 1985, 146 (2) 211-223 - Plasma cross-circulation which resembles plasma exchange and plasma perfusion over charcoal and resin adsorbents were carried out using rats with galactosamine (GalN)-induced hepatic failure to investigate the effects of those plasma purification procedures on damaged liver function. Twenty-four hr after the injection of GalN, the plasma treatment procedures were performed at a plasma flow rate of $0.1 \mathrm{ml} / \mathrm{min}$ for $6 \mathrm{hr}$. Forty-eight hr after the injection of GalN, ATP synthesis in liver mitochondrial function, and ATP and total adenine nucleotide contents in the liver, which were markedly reduced by the GalN administration, were increased by both plasma cross-circulation and plasma perfusion over adsorbents. These results suggest that both plasma purification procedures improve the deterioration of mitochondrial phosphorylation activity and produce an augmented high energy status in the liver. In the histological study of the liver, volume ratio of hepatic parenchyma in the GalN-treated liver to that in the normal liver was significantly higher in rats treated with plasma perfusion than those with sham-perfusion. An efficient removal of the hepatotoxic metabolites from the plasma, therefore, decelerates the progress of GalN induced-liver tissue necrosis, if rats with GalN-induced hepatic failure are treated in an early stage.

hepatic failure rats; plasma purification, liver pathophysiology

The pathogenesis of coma in hepatic failure is not clearly defined, although either an accumulation of toxic metabolites or a deficiency of essential products is likely to be an important cause. The limitations of conventional therapy have led to increasing interest in the development of liver support systems. Among the various liver support systems, cross-circulation is the most promising approach. However, immunological problems and the potential dangers to the donor have limted its use (Burnell et al. 1967, 1973).

Sabin and Merritt (1968) described the effectiveness of plasma exchange, since plasma contains essential metabolites and can be conveniently stored for long

Received November 14, 1984 ; accepted for publication, February 22, 1985. 
periods. Recently plasma exchange in patients has been facilitated by the continuous plasmapheresis technique with the wide use of a membrane plasma separator or the centrifugal technique. The role of plasma exchange includes the possible removal of toxic metabolites and the supplementing of essential products. However, due to the limited availability of fresh plasma, the amount of plasma available for exchange tends to be insufficient.

On the other hand, with plasma perfusion over adsorbents, larger amounts of patient plasma can be treated, since plasma products are not needed. Direct hemoperfusion over charcoal has been widely applied in the treatment of hepatic failure (Gazzard et al. 1974). However, the survival rate was poor owing to hypotensive reactions following platelet aggregation (Williams 1978). Willson et al. $(1972,1974)$ concluded that the anion exchange resin is useful for the removal of protein-bound substances of variable toxic potential, known to be extracted by the liver and excreted in the bile. However, low biocompatibility of the resin has prevented its clinical application. Thereafter, the plasma separation principle using a membrane plasma separator was introduced by the authors (Ouchi et al. 1978; Asanuma et al. 1981). Plasma perfusion over charcoal and anion exchange resin was blood cell compatible and effective for the removal of middle molecular and protein-bound substances accumulated in the blood in patients with hepatic failure.

The efficacy of plasma exchange and plasma perfusion over adsorbents in the treatment of patients with hepatic failure, however, is not proven, since the etiology and/or the severity of hepatic disorders are completely different in each patient. The hepatic failure rat model induced by galactosamine was used for the assessment of the various liver support systems because of its high reproducibility and reversibility (Blitzer et al. 1978; Chirito et al, 1977, 1979; Sommer et al. 1979 ; Mohsini et al. 1980 ; O'Neill et al. 1982).

To investigate the effects, on the liver pathophysiology, of plasma cross -circulation (which resembles plasma exchange and may be able to exchange larger amount of plasma) and plasma perfusion over charcoal and anion exchange resin, mitochondrial function, adenine nucleotide metabolism and histology of the liver were studied using galactosamine-induced hepatic failure rats.

\section{Materials and Methods}

Cannulation of the rats

Male SD rats weighing 200-250 g were used. Under ether inhalation anesthesia, both femoral veins were exposed and cannulas were passed into the inferior vena cava. The cannula used was siliconized polyethylene tubing with an inner diameter of $0.5 \mathrm{~mm}$ and an outer diameter of $1.0 \mathrm{~mm}$. The cannulas were filled with saline containing $20 \mathrm{IU} / \mathrm{ml}$ of heparin and clamped. The cannulation was routinely carried out 1 or 2 days before the plasma treatment procedures to avoid bleeding from the wound during heparinization of the animal. 


\section{Plasma treatment procedures}

The animals were given galactosamine hydrochloride (GalN, Sigma Co., St. Louis, Missouri, U.S.A.) in a dose of $1.2 \mathrm{~g} / \mathrm{kg}$ body weight intraperitoneally $24 \mathrm{hr}$ before the initiation of the plasma treatment procedures. The animals selected for the experiments had serum GOT levels of more than 1,000 units, in blood samples taken immediately before the plasma treatment procedures. They showed grade I coma as defined for GalN treated rats by Chang's group (Chirito et al. 1977, 1979; Mohsini et al. 1980). Forty-nine of the 73 rats that received GalN injection were selected and assigned to the various treatment regimens. Plasma treatment and matched sham-treatment procedures were carried out on the same day using the same batches of rats.

During the plasma treatment procedures, the animal was placed in a restrainer and the procedures were carried out with the animal fully conscious. A hollow, cellulose acetate, fiber filter, $80 \mathrm{~mm}$ in length, $97 \mathrm{~cm}^{2}$ in effective surface area and $0.2 \mu \mathrm{m}$ in maximum pore size was used as a plasma separator. This is an experimental device obtained from Asahi Medical Co., Tokyo. Flow rates of blood and plasma were regulated by pumps (Holter Pump, Extracorporeal, King of Prussia, Pa., U.S.A.) to $1 \mathrm{ml} / \mathrm{min}$ and $0.1 \mathrm{ml} / \mathrm{min}$, respectively. For the priming of the circuit, approximately $4 \mathrm{ml}$ was required including $1 \mathrm{ml}$ for a plasma separator. To avoid loss of blood from the animals, the circuits were primed with blood and plasma prepared in advance except for a part of the plasma separator. Heparin was generally given in total doses of $100 \mathrm{IU}$ in each rat for plasma cross-circulation and 300 IU for plasma perfusion over adsorbents.

Plasma cross-circulation was carried out between GalN treated and normal rats for $6 \mathrm{hr}$ using two plasma separators and two roller pumps with closed circuits (Fig. 1). For sham-circulation, GalN injected rats were singly-circulated for $6 \mathrm{hr}$ with an exactly identical

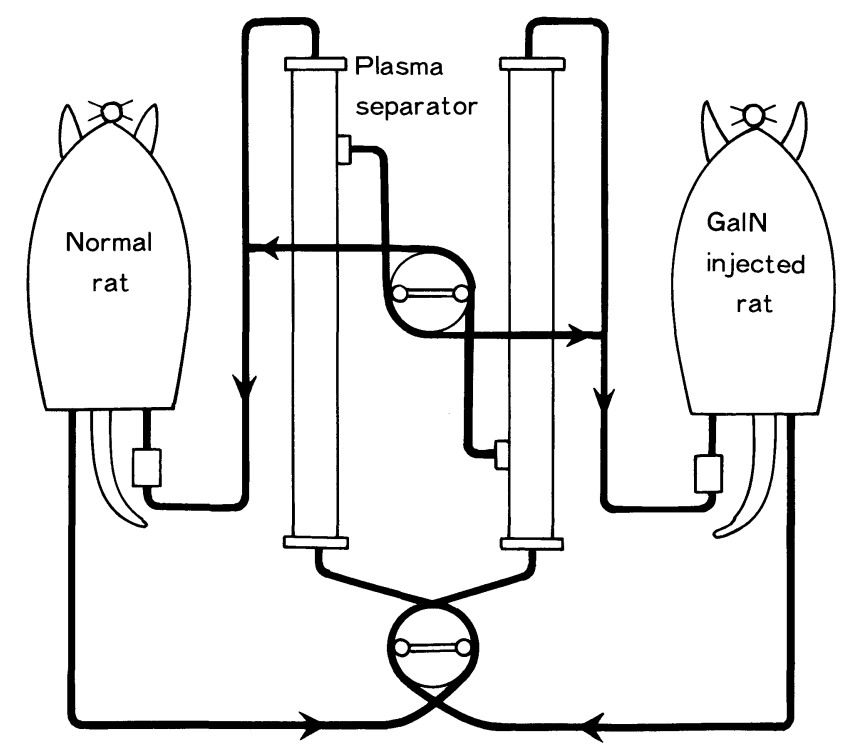

Fig. 1. Schematic diagram of plasma cross-circulation system. Twenty-four hr after the injection of galactosamine (GalN), plasma cross-circulation between GalN -treated and normal partner rats was carried out for $6 \mathrm{hr}$. Plasma was separated at a rate of $0.1 \mathrm{ml} / \mathrm{min}$ from blood which flowed at a rate of $1 \mathrm{ml} / \mathrm{min}$ using two cellulose acetate hollow fiber filters and cross-circulated between two rats. 
method to plasma cross-circulation.

For plasma perfusion over adsorbents in GalN treated rats, separated plasma was continuously perfused through a column containing $2 \mathrm{~g}$ of petroleum pitch charcoal (Takeda Pharmaceutical Co., Tokyo) and $1.6 \mathrm{~g}$ of anion exchange resin (Dowex-l, Bio-Rad Laboratories, Richmond, Calif., U.S.A.) for $6 \mathrm{hr}$ (Fig. 2). For sham-perfusion, GalN injected rats were subjected to plasma perfusion through a column containing glass beads instead of adsorbents. In the normal control rats all steps were done in same sequence as in the sham-treatment groups except that no GalN was administered.

To study the blood compatibility of the procedure, normal rats were sacrificed immediately after the completion of singly-plasma circulation for $6 \mathrm{hr}$, and blood was used for hematological analyses. In addition, animals were sacrificed $18 \mathrm{hr}$ after the completion of the procedure, and the livers were resected for analysis as the controls.

After the completion of the plasma treatment procedures, all rats were given water ad libidum. Five per cent dextrose in normal saline solution was given intravenously through the cannula at a rate of $0.59 \mathrm{ml} / \mathrm{hr}$ until death. The surviving rats were sacrificed $18 \mathrm{hr}$ after the completion of procedures (i.e., $48 \mathrm{hr}$ after GalN injection) and their blood and livers were analyzed.

\section{Biochemical estimations}

Blood examinations. Glutamic oxaloacetic transaminase (GOT), glutamic pyruvic transaminase (GPT), alkaline phosphatase and total bilirubin levels were measured using Uni-Kit (Chugai Pharmaceutical Co., Tokyo).

Mitochondrial respiratory function of the liver. The liver was excised and $10 \%$ homogenate was prepared with cold $0.25 \mathrm{M}$ sucrose ( $\mathrm{pH} 7.4$ ). The mitochondrial fraction was separated using Hogeboom and Schneider's method (Hogeboom and Schneider 1948)

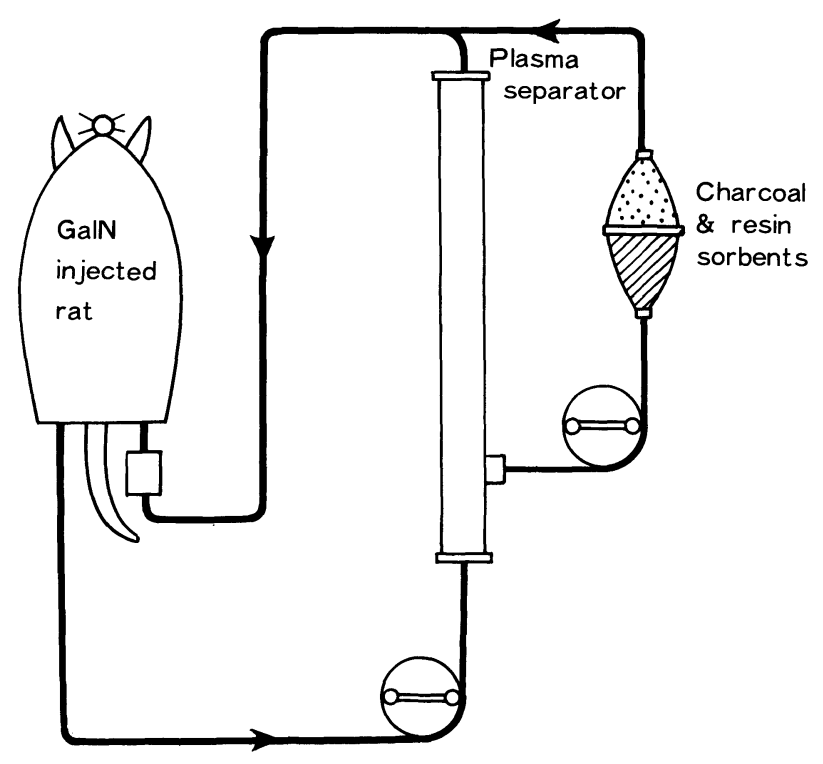

Fig. 2. Schematic diagram of plasma perfusion over adsorbents. Twentyfour hr after the injection of galactosamine (GalN), plasma perfusion through a column containing $2 \mathrm{~g}$ of petroleum pitch charcoal and $1.6 \mathrm{~g}$ of anion exchange resin was carried out for $6 \mathrm{hr}$. Plasma was separated at a rate of $0.1 \mathrm{ml} / \mathrm{min}$ using the cellulose acetate hollow fiber filter from blood which flowed at a rate of $1 \mathrm{ml} / \mathrm{min}$ and perfused. 
and was resuspended at a protein concentration of $20 \mathrm{mg} / \mathrm{ml}$. Mitochondrial respiratory function was measured polarographically with an oxygen consumption meter (Yanaco, Tokyo). Details have been previously described (Koyama et al. 1980).

Adenine nucleotide metabolism of the liver. The concentrations of ATP, ADP, and AMP in the liver specimens, which had been rapidly frozen in liquid nitrogen, were measured enzymatically by standard methods of spectrophotometric readings at $340 \mathrm{~nm}$ (Lamprecht and Trautschold 1965; Adams 1965). Boehringer test kits were used for the measurements (Boehringer Co., London, U.K.).

Histology of the liver. With the H-E stained section of the liver, point-counting was done on hepatic parenchymal cells in 30 randomized field samples using an occular micrometer with a grating consisting of $21 \times 21$ points of intersection. When the number of points of intersection of the grating falling on the nucleus is denoted by $\mathrm{Np}$, hepatic parenchymal volume $N_{c}$ is expressed by the following equation (Weibel et al. 1966) :

$$
N_{c}=\frac{\sum^{n} N P i}{n 441}(n=30)
$$

Then the volume ratio of hepatic parenchyma in the GalN-treated liver to that in the normal liver $(V v)$ is expressed by:

$$
V v=N c(\text { gal }) / N c(\text { nor }) \times 100(\%)
$$

Where $N c$ (gal) represents the hepatic parenchymal volume in the GalN treated liver and $\mathrm{Nc}$ (nor) in the normal control liver.

\section{Results}

Blood cell compatibility of systems

As shown in Table 1, platelet counts showed a significant decrease to $58 \%$ of the initial values after $6 \mathrm{hr}$ of plasma separation procedure. White blood cell counts, in contrast, increased to $117 \%$ of the initial values, but these changes were not significant. Levels of red blood cell counts, hemoglobin and hematocrit showed little changes after the procedures.

\section{Survival rates of animals}

Survival rate of the rats was $75 \%$ (6 of 8 survived) in the plasma crosscirculation group as against $40 \%$ (4 of 10 survived) in the sham-circulation group $48 \mathrm{hr}$ after the injection of GalN. There existed, however, no statistically significant difference between the two groups. There were no deaths in partner rats cross-circulated with GalN treated rats up to at least $18 \mathrm{hr}$ after the procedure.

TABLE 1. Effects of plasma treatment on hematology in normal control rats

\begin{tabular}{lcccccc}
\hline & $\begin{array}{c}\text { Number } \\
\text { of } \\
\text { rats }\end{array}$ & $\begin{array}{c}\text { White blood } \\
\text { cell counts } \\
\left(\times 10^{4} / \mathrm{mm}^{3}\right)\end{array}$ & $\begin{array}{c}\text { Red blood } \\
\text { cell counts } \\
\left(\times 10^{4} / \mathrm{mm}^{3}\right)\end{array}$ & $\begin{array}{c}\text { Hemoglobin } \\
(\mathrm{g} / 100 \mathrm{ml})\end{array}$ & $\begin{array}{c}\text { Hematocrit } \\
(\%)\end{array}$ & $\begin{array}{c}\text { Platelet } \\
\text { counts } \\
\left(\times 10^{5} / \mathrm{mm}^{3}\right)\end{array}$ \\
\hline $\begin{array}{c}\text { Before } \\
\text { treatment }\end{array}$ & 4 & $1.36 \pm 0.38$ & $558.7 \pm 132.2$ & $12.5 \pm 2.1$ & $36.2 \pm 7.5$ & $5.49 \pm 1.38$ \\
$\begin{array}{c}\text { After } \\
\text { treatment }\end{array}$ & 4 & $1.60 \pm 0.24$ & $576.0 \pm 43.6$ & $12.9 \pm 0.4$ & $37.0 \pm 1.8$ & $3.19 \pm 0.7^{*}$ \\
\hline
\end{tabular}

Results given are means \pm S.D.

* Significantly different from values before plasma treatment at level of $p<0.05$ (Student's $t$-test). 
The plasma perfusion group, in contrast, achieved a significantly higher survival rate of $83.3 \%$ ( 5 of 6 survived) as compared with the sham-perfusion group of $33.3 \%$ (4 of 12 survived, Chi Square $p<0.001$ ).

In most of the surviving rats coma advanced to grade II in both the plasma treatment and the sham-treatment groups, at the time of sacrifice. In the rats which died within $48 \mathrm{hr}$ of injection of GalN, onset of grade III coma, in most cases, took place 1 to $2 \mathrm{hr}$ before death.

\section{Liver function tests}

Hepaplastin test values were less than $10 \%$ in both the plasma treatment and the sham-treatment groups not only at the initiation of the treatment but also at the time of sacrifice.

Values of GOT and GPT were markedly elevated immediately before the plasma treatment procedures, showing approximately 1,500 and 1,200 Karmen units, respectively. No significant differences in these values were found between the plasma theatment and the sham-treatment groups before the procedures. After plasma cross-circulation for $6 \mathrm{hr}$, GOT and GPT values in GalN treated rats almost equalled those in partner rats. As shown in Table 2, average levels of GOT and GPT in the plasma cross-circulation group were significantly lower than those in the sham-circulation group $48 \mathrm{hr}$ after GalN injection. Although rats treated with plasma perfusion over adsorbents had lower values of GOT and GPT than those with sham-perfusion, there was no statistical difference. There were no significant differences between the plasma treatment and the sham-treatment groups in either total bilirubin or alkaline phosphatase levels.

TABLE 2. Liver function tests $48 \mathrm{hr}$ after galactosamine injection in rats which received plasma treatment

\begin{tabular}{lccrrr}
\hline & $\begin{array}{c}\text { Number } \\
\text { of } \\
\text { rats }\end{array}$ & $\begin{array}{c}\text { Total } \\
\text { bilirubin } \\
(\mathrm{mg} / 100 \mathrm{ml})\end{array}$ & $\begin{array}{c}\text { GOT } \\
\text { (Karmen } \\
\text { units })\end{array}$ & $\begin{array}{c}\text { GPT } \\
\text { (Karmen } \\
\text { units) }\end{array}$ & $\begin{array}{c}\text { Alkaline } \\
\text { phophatase } \\
\text { (K-A units })\end{array}$ \\
\hline $\begin{array}{l}\text { Plasma } \\
\text { cross-circ. }\end{array}$ & 6 & $1.2 \pm 0.8$ & $1745 \pm 295 \S$ & $605 \pm 111 \S$ & $46.7 \pm 5.0$ \\
Partner & 8 & $0.2 \pm 0.1$ & $186 \pm 13$ & $44 \pm 23$ & $23.9 \pm 4.0$ \\
$\begin{array}{l}\text { Sham-circ. } \\
\text { Sorbent } \cdot \text { plasma }\end{array}$ & 4 & $0.8 \pm 0.1$ & $2830 \pm 382$ & $2084 \pm 445$ & $52.4 \pm 9.6$ \\
$\quad$ perf. & 5 & $0.6 \pm 0.2$ & $1460 \pm 516$ & $1235 \pm 486$ & $40.1 \pm 11.5$ \\
$\begin{array}{l}\text { Sham-perf. } \\
\text { Normal control }\end{array}$ & 4 & $0.8 \pm 0.2$ & $2047 \pm 621$ & $1608 \pm 519$ & $50.8 \pm 18.2$ \\
\end{tabular}

Results given are means \pm S.D.

Circ., Circulation; Perf., Perfusion.

$\S$ Significantly different from values in the sham-treatment group at level of $p<$ 0.001 (Student's $t$-test). 


\section{Mitochondrial respiratory function in the liver}

In tests of mitochondrial respiratory function of the liver $48 \mathrm{hr}$ after GalN injection (Table 3), ATP synthesis and oxygen consumption in state $3\left(\mathrm{~S}_{3}\right)$ in the plasma cross-circulation group were significantly higher than those in the shamcirculation group. No significant differences were observed between the two groups in respiratory control ratio $(\mathrm{RC})$ and $\mathrm{ADP} / \mathrm{O}$ ratio $(\mathrm{P} / \mathrm{O})$. Significantly reduced levels of $\mathrm{RC}, \mathrm{P} / \mathrm{O}$ and $\mathrm{ATP}$ synthesis were demonstrated in partner rats cross-circulated with GalN rats in comparison with those in control rats even 18 hr after the completion of the procedure. ATP synthesis in the plasma perfusion group was significantly higher than that in the sham-perfusion group. No significant differences were seen in other parameters between the two groups.

\section{Adenine nucleotide concentrations in the liver}

In tests of adenine nucleotide metabolism in the liver $48 \mathrm{hr}$ after GalN injection (Table 4), concentrations of ATP, ADP and total adenine nucleotide $(\mathrm{ATP}+\mathrm{ADP}+\mathrm{AMP})$ were significantly higher in the plasma cross-circulation group than in the sham-circulation group. No significant difference was found in AMP levels between the two groups. Adenine nucleotide concentrations except for AMP, were significantly lower in partner rats than those in control rats. In rats treated with plasma perfusion over adsorbents, ATP and total adenine nucleotide cocentrations were significantly higher than those in rats treated with sham-perfusion. There were no significant differences between the two groups, however, in ADP and AMP concentrations.

TABLE 3. Mitochondrial respiratory function in the liver $48 \mathrm{hr}$ after galactosamine injection in rats which received plasma treatment

\begin{tabular}{lccccc}
\hline & $\begin{array}{c}\text { Number } \\
\text { of } \\
\text { rats }\end{array}$ & RC & $\mathrm{P} / \mathrm{O}$ & $\begin{array}{c}\mathrm{S}_{3} \\
\text { (natom/mg } \\
\text { protein/min) }\end{array}$ & $\begin{array}{c}\text { ATP syn } \\
\text { (nmole/mg } \\
\text { protein/min })\end{array}$ \\
\hline Plasma cross-circ. & 6 & $2.26 \pm 0.19$ & $1.04 \pm 0.23$ & $97.2 \pm 5.1 \S$ & $109.8 \pm 18.4 \dagger$ \\
$\begin{array}{l}\text { Partner } \\
\text { Sham-circ. }\end{array}$ & 8 & $3.18 \pm 0.13$ & $1.40 \pm 0.19$ & $119.1 \pm 16.5$ & $163.3 \pm 13.2$ \\
$\begin{array}{l}\text { Sorbent } \text { p plasma } \\
\text { perf. }\end{array}$ & 4 & $1.96 \pm 0.27$ & $1.08 \pm 0.10$ & $49.9 \pm 26.8$ & $55.6 \pm 18.7$ \\
$\begin{array}{l}\text { Sham-perf. } \\
\text { Normal control }\end{array}$ & 5 & $2.88 \pm 0.34$ & $1.43 \pm 0.18$ & $85.3 \pm 17.7$ & $135.5 \pm 20.3 \dagger$ \\
\hline
\end{tabular}

Results given are means \pm s.D.

Circ., Circulation; Perf., Perfusion.

$\mathrm{RC}$, respiratory control; $\mathrm{P} / \mathrm{O}, \mathrm{ADP} / \mathrm{O}$ ratio $; \mathrm{S}_{3}$, oxygen consumption in state 3 ; ATP syn, ATP synthesis. $\S$ and $\dagger$, Significantly different from values in the shamtreatment groups at levels of $p<0.001$ and $p<0.01$, respectively (Student's $t$-test). 


\section{Histological study of the liver}

Microscopic study of the liver showed extensive areas of hepatocellular necrosis, portal inflammation, enlarged Kupffer cells and bile duct proliferation which were prominent both in the plasma treatment and the sham-treatment groups. Volume ratio of hepatic parenchyma $(\mathrm{Vv})$ was, however, significantly higher in the plasma perfusion group than in the sham-perfusion group (Fig. 3).

TABLE 4. Adenine nucleotide contents in the liver $48 \mathrm{hr}$ after galactosamine injection in rats which received plasma treatment

\begin{tabular}{|c|c|c|c|c|c|}
\hline & $\begin{array}{l}\text { Number } \\
\text { of } \\
\text { rats }\end{array}$ & $\begin{array}{l}\text { ATP } \\
\qquad(\mu \text { mole }\end{array}$ & $\begin{array}{l}\text { ADP } \\
\text { /g liver weig }\end{array}$ & AMP & Total AN \\
\hline Plasma cross-circ. & 6 & $1.96 \pm 0.18 \S$ & $0.82 \pm 0.10^{*}$ & $0.18 \pm 0.05$ & $2.96 \pm 0.31 \S$ \\
\hline Partner & 8 & $2.14 \pm 0.05$ & $0.91 \pm 0.05$ & $0.30 \pm 0.01$ & $3.39 \pm 0.15$ \\
\hline Sham-circ. & 4 & $1.37 \pm 0.22$ & $0.69 \pm 0.18$ & $0.24 \pm 0.05$ & $2.31 \pm 0.36$ \\
\hline Sorbent plasma perf. & 5 & $2.02 \pm 0.27^{*}$ & $0.92 \pm 0.13$ & $0.22 \pm 0.11$ & $3.15 \pm 0.34^{*}$ \\
\hline Sham-perf. & 4 & $1.53 \pm 0.24$ & $0.79 \pm 0.16$ & $0.29 \pm 0.13$ & $2.61 \pm 0.28$ \\
\hline Normal control & 9 & $2.51 \pm 0.19$ & $1.17 \pm 0.06$ & $0.31 \pm 0.05$ & $3.93 \pm 0.20$ \\
\hline
\end{tabular}

Results given are means \pm S.D.

Circ., Circulation; Perf., Perfusion.

Total AN : Total adenine nucleotide (ATP + ADP + AMP)

$\S$ and *, Significantly different from values in the sham-treatment groups at levels of $p<0.001$ and $p<0.05$, respectively (Student's $t$-test).

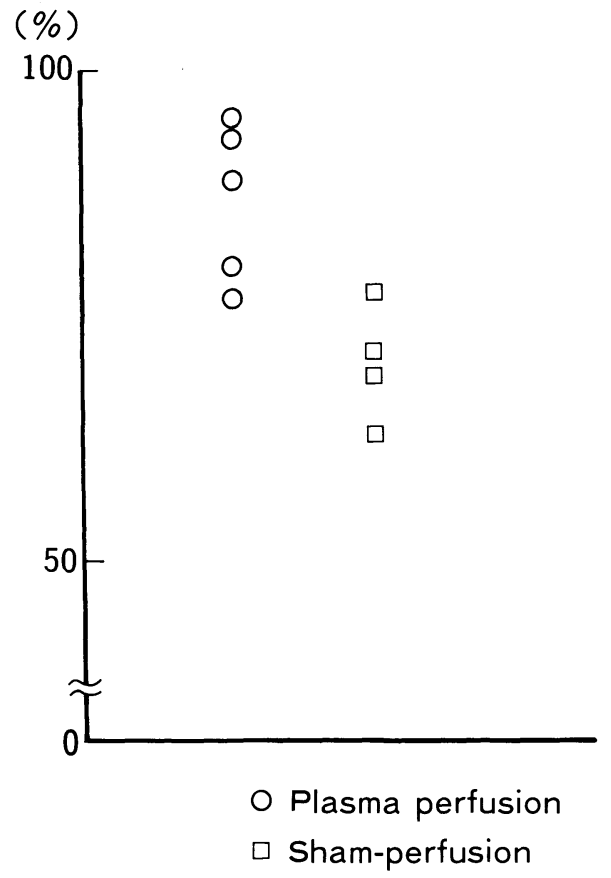

Fig. 3. Volume ratio of hepatic parenchyma in the GalN-treated liver to that in the normal liver $(\mathrm{Vv})$ measured by pointcounting method in the histological study of the liver obtained 48 hours after galactosamine injection. A statistically significant difference was present between the mean values of the plasma perfusion and the sham-perfusion groups : $p<0.01$ (Student's $t$-test). 


\section{Discussion}

With respect to the removal of toxic substances from patients with hepatic coma treated in our department, blood levels of bilirubin, free fatty acids, ammonia and aromatic amino acids showed slight to moderate decreases after plasma exchange (Ouchi et al. 1983). In most cases, however, the levels returned to the pretreatment values on the next day due to re-equilibration between blood and tissue pools. Our previous studies (Ouchi et al. 1978; Asanuma et al. 1981) on plasma perfusion over charcoal and anion exchange resin demonstrated that charcoal could remove free fatty acids and aromatic amino acids, whereas resin could remove bilirubin, bile acids and other still unknown protein-bound substances. As far as the removal of toxic substances was concerned, plasma exchange was less effective than plasma perfusion, although the supply of fresh plasma must contribute a lot to correcting deranged coagulation status and supplying other essential factors in these patients. Removal of protein-bound substances seemed to be important for the reversal of coma, although long-term survival was still difficult to obtain by the sole use of these procedures.

High doses of GalN develop an animal model of fulminant hepatic failure that substantially resembles human fulminant hepatitis in its clinical and biochemical manifestations (Chirito et al. 1979). The hepatic lesion must be potentially reversible if the effects of treatment regimens are to be meaningfully tested. Plasma treatment procedures were begun $24 \mathrm{hr}$ after the injection of GalN because GalN is undetectable in blood $3 \mathrm{hr}$ after its intraperitoneal injection (Yamazaki et al. 1980). Since the plasma treatment procedures themselves were not shown to remove GalN, biochemical alteration of the liver would underly the effects of plasma treatment. Investigation of the liver by sacrificing the surviving rats was done $48 \mathrm{hr}$ after GalN injection at the time when liver damage was expected to be maximum (Lesch et al. 1970; Decker and Keppler 1972). Our previous studies (Mitsui et al. 1982) demonstrated that maximum damage in mitochondrial function of the liver had occurred by $48 \mathrm{hr}$. Since the regeneration of the liver parenchyma reached maximum $72 \mathrm{hr}$ after GalN injection (Lesch et al. 1970), the differences in biochemical alterations of the liver between treated and untreated surviving rats must be most prominent $48 \mathrm{hr}$ after GalN injection. Therefore the changes in hepatic mitochondrial function and adenine nucleotide levels were investigated of the rats only up to $48 \mathrm{hr}$ after GalN injection. Study of the long-term survival rate was thus sacrificed.

Although platelet counts were slightly reduced, the plasmapheresis procedures produced no significant hematological changes. Since our previous studies (Mitsui et al. 1982) of the blood-biochemical parameters in rats after GalNinjection had revealed insignificant changes in ammonia and glucose levels, measurements were not carried out in the present study.

Intraperitoneal injection of GalN did not produce hepatic necrosis and 
hepatic failure with a high degree of reproducibility in this experiments. Efforts to perform simultaneous matched studies using rats from the same batch as test rats has solved this problem. The pre-treatment GOT and GPT values of the plasma treatment and the sham-treatment groups were closely identical. It can be inferred that there was no difference between the two groups in the degree of hepatocellular damage.

In rats with plasma treatment at a plasma flow rate of $0.1 \mathrm{ml} / \mathrm{min}$ for $6 \mathrm{hr}$ corresponds to approximately $10 l$ of treating volume of plasma in human adults. To obtain plasma for exchange in rats, many donor rats must be sacrificed. Plasma cross-circulation which resembles plasma exchange was, therefore, undertaken. Achievement of complete equilibrium of blood in both GalN treated and normal partner rats was demonstrated by identical serum levels of GOT and GPT in both, immediately after the completion of the plasma cross-circulation procedure. Thereafter, the plasma cross-circulation group showed slower elevation of GOT and GPT for $48 \mathrm{hr}$. This suggests that plasma cross-circulation decelerates the progress of hepatic necrosis. Although survival rate was not significantly improved, plasma cross-circulation enhanced ATP synthesis in the liver by the acceleration of oxidative phosphorylation as demonstrated by higher level of state 3 respiration. In addition, it significantly improved ATP, ADP and total adenine nucleotide concentrations in the liver which were markedly reduced by GalN administration. Ukikusa et al (1981) carried out cross-circulation between $70 \%$ hepatectomized rabbits and normal rabbits for one hr, and found the energy charge (Atkinson 1968) of the remnant liver, which had been markedly reduced by hepatectomy and increased by cross-circulation. They pointed out that crosscirculation may be effective for regeneration of the remnant liver. It must be emphasized that plasma cross-circulation also prevented the deterioration of mitochondrial phosphorylate activity and produced an augmented high energy status in the GalN-treated liver as far as treated in an early stage of hepatic coma. A removal of toxic metabolites as well as an influx of fresh plasma by plasma cross-circulation may decelerate the progress of hepatic necrosis induced by GalN injection.

Existence of hepatotoxic substances in the blood of rats treated with GalN was proved, since the deterioration of mitochondrial function and adenine nucleotide metabolism of the liver was demonstrated in normal partner rats crosscirculated with GalN injected rats. The effects of plasma perfusion over adsorbents on the hepatic mitochondrial respiratory function and the energy status were very similar to those of plasma cross-circulation. The hepatotoxic substances were removed by the dilution of plasma in plasma cross-circulation and by adsorption in plasma perfusion over adsorbents. Closely identical efficiency of plasma perfusion with plasma cross-circulation for the partial improvement of mitochondrial respiratory dysfunction suggests that the regenerative process of GalN-induced hepatic necrosis may occur only with the efficient removal of 
hepatotoxic substances from the plasma. This was strongly supported by the evidence of histological studies of the liver showing a siginficantly high volume ratio of hepatic parenchyma in the plasma perfusion group as compared to that in the sham-perfusion group. A study carried out by Chirito et al (1977) demonstrated that one hr charcoal hemoperfusion in the early stage of coma significantly improved the long-term survival of GalN-induced hepatic failure rats. It was proposed from the analyses that some toxins may be in the middle molecular weight range. Further studies must be carried out to clarify the role of proteinbound substances in the pathogenesis of hepatic coma. The significant contribution of endotoxins to the pathogenesis of GalN hepatitis has been reported based upon its clinical manifestations, i.e. pyrogen reaction, disseminated intravascular coagulation and arterial hypotension (Grün et al. 1976). Perhaps endotoxins may be considered as one of the hepatotoxic substances and can be effectively removed by charcoal.

It is important to note that $\mathrm{RC}$ and $\mathrm{P} / \mathrm{O}$ represent the intactness of liver mitochondria. Despite the improvement of ATP synthesis in liver mitochondrial function which was demonstrated in the rats which received plasma treatment, levels of $\mathrm{RC}$ and $\mathrm{P} / \mathrm{O}$ did show no significant increase. Hence it could be suggested that impairment of liver mitochondrial function still persisted. The lack of improvement in the grade of coma, after plasma treatment, was consistent with this finding. The present study failed to prove the effectiveness of plasma treatment in prolonging the life of the rats. In addition, the effectiveness of plasma purification on single time hepatic necrosis induced by GalN administration in animals may be characteristically different from that on repeated or continuous hepatic necrosis induced by viral exposures in humans. Despite these the authors believe that combined application of plasma perfusion and fresh plasma infusion would be beneficial for the deceleration of the progressive damages of the liver tissues, if patients with hepatic failure are treated in an early stage of coma.

\section{References}

1) Adams, H. (1965) Adenosine-5'-diphosphate and adenosine-5'-monophosphate. In: Methods of Enzymatic Analysis, edited by H.U. Bergmeyer, Academic press, New York, pp. 573-577.

2) Asanuma, Y., Malchesky, P., Smith, J., Zawicki, I., Werynski, A., Carey, W., Ferguson, D., Hermann, R., Kayashima, K. \& Nose, Y. (1981). Chronic ambulatory liver support by membrane plasmapheresis with on-line detoxification. Trans. Amer. Soc. artif. intern. Organs, 27, 416-422.

3) Atkinson, D.E. (1968) The energy charge of the adenylate pool as a regulatory parameter. Interaction with feedback modifiers Biochemistry, 7, 4030-4034.

4) Blitzer, B.L., Waggoner, J.G., Jones, E.A., Gralnick, H.R., Towne, D., Butler, J., Weise, U., Kopin, I.J., Walters, I., Teychenne, P.F., Goodman, D.G. \& Berk, P.D. (1978) A model of fulminant hepatic failure in the rabbit. Gastroenterology, 74, 664-671. 
5) Burnell, J.M., Dawborn, J.K., Epstein, R.B., Gutman, R.A., Leinbach, G.E. \& Thomas, E.D. (1967) Acute hepatic coma treated by cross-circulation or exchange transfusion. New Engl. J. Med., 276, 935-943.

6) Burnell, J.M., Runge, C., Saunders, F.C., Thomas, E.D. \& Volwiler, W. (1973) Acute hepatic failure treated by cross circulation. Arch. intern. Med., 132, 493-498.

7) Chirito, E., Reiter, B., Lister, C. \& Chang, T.M.S. (1977) Artificial liver : The effect of ACAC microcapsulated charcoal hemoperfusion on fulminant hepatic failure. Artif. Organs, 1, 76-83.

8) Chirito, E., Lister, C. \& Chang, T.M.S. (1979) Biochemical, hematological and histological changes in a fulminant hepatic failure rat model for artificial liver assessment. Artif. Organs, 3, 42-46.

9) Decker, K. \& Keppler, D. (1972) Galactosamine induced liver injury. In: Progress in Liver Diseases, edited by H. Popper \& F. Schaffner, Grune and Stratton, New York and London, pp. 183-199.

10) Gazzard, B.G., Weston, M.J., Murray-Lyon, I.M., Flax, H., Record, C. O., Portmann, B., Langley, P.G., Dunlop, E.H., Mellon, P.J. \& Ward, M.B. (1974) Charcoal haemoperfusion in the treatment of fulminant hepatic failure. Lancet, 1, 1301-1307.

11) Grün, M., Liehr, H. \& Rasenack, U. (1976) Significance of endotoxaemia in experimental "galactosamine-hepatitis" in the rat. Acta hepato-gastroenterol., 23, 64-81.

12) Hogeboom, G.H. \& Schneider, W.C. (1984) Isolation of intact mitochondria from rat liver. J. biol. Chem., 172, 619-635.

13) Koyama, K., Ito, K., Ouchi, K. \& Sato, T. (1980) Mitochondrial function of rat liver in biliary obstruction. Tohoku J. exp. Med., 131, 59-69.

14) Lamprecht, W. \& Trautschold, I. (1965) Adenosine-5'-triphosphate. Determination with hexokinase and glucose-6-phosphate dehydrogenase. In : Methods of Enzymatic Analysis, edited by H.U. Bergmeyer, Academic Press, New York, pp. 543-551.

15) Lesch, R., Reutter, W., Keppler, D. \& Decker, K. (1970) Liver restitution after acute galactosamine hepatitis: Autoradiographic and biochemical studies in rats. Exp. mol. Path., 12, 58-69.

16) Mitsui, T., Ashino, Y., Omokawa, S., Okabe, K., Imaoka, Y., Fukaya, H., Takagi, Y., Koyama, K. \& Sato, T. (1982) Pathophysiology of galactosamine-induced hepatic failure. Jap. J. digest. Dis., 79, 493. (Japanese)

17) Mohsini, K., Lister, C. \& Chang, T.M.S. (1980) The effects of homologous crosscirculation and in situ liver perfusion on fulminant hepatic failure rats. Artif. Organs, 4, 171-179.

18) O'Neill, P.L., Baumgartner, D., Lewis, W.I., Zweber, B.A. \& Sutherland, D.E. (1982) Cell-free supernatant from hepatocyte cultures improves survival of rats with chemically induced acute liver failure. J. surg. Res., 32, 347-359.

19) Ouchi, K., Piatkiewicz, W., Malchesky, P.S., Carey, W.D., Hermann, R.E. \& Nosé, Y. (1978) An efficient, specific and blood compatible sorbent system for hepatic assist. Trans. Amer. Soc. artif. intern. Organs, 24, 246-249.

20) Ouchi,K., Asanuma, Y., Owada, Y., Koyama, K. \& Sato, T. (1983) Comparisons of 3 liver support systems with patients: RP-6 hemodialysis, plasma perfusion over multiple sorbents and plasma exchange. In: Plasmapheresis, New Trends in Therapeutic Applications, edited by Y. Nosé, P.S. Malchesky \& J.W. Smith, ISAO Press, Cleveland, pp. 215-222.

21) Sabin, S. \& Merritt, J.A. (1968) Treatment of hepatic coma in cirrhosis by plasmapheresis and plasma infusion (plasma exchange). Ann. intern. Med., 68, 1-7.

22) Sommer, B.G., Sutherland, D.E.R., Matas, A.J., Simmons, R.L. \& Najarian, J.S. (1979) Hepatocellular transplantation for treatment of D-galactosamine-induced acute liver failure in rats. Transplant. Proc., 11, 578-584.

23) Ukikusa, M., Ozawa, K., Shimahara, Y., Sawanishi, K. \& Tobe, T. (1981) The effects of cross-circulation and charcoal hemoperfusion on adenylate energy charge of the 
remnant liver after major hepatic resection. Artif. Organs, 5, 67-71.

24) Weibel, E.R., Kistler, G.S. \& Scherle, W.F. (1966) Practical sterelogical methods for morphometric cytology. J. Cell Biol., 30, 23-38.

25) Williams, R. (1978) Trials and tribulations with artficial liver support. Gut, 19, 578-583.

26) Willson, R.A., Webster, K.H., Hofmann, A.F. \& Summerskill, W.H. (1972) Toward an artificial liver: In vitro removal of unbound and protein-bound plasma compounds related to hepatic failure. Gastroenterology, 62, 1191-1199.

27) Willson, R.A., Hofmann, A.F. \& Kuster, G.G. (1974) Toward an artificial liver : II. Removal of cholephilic anions from dogs with biliary obstruction, by hemoperfusion through charged and uncharged resins. Gastroenterology, 66, 95-107.

28) Yamazaki, Z., Fujimori, Y. \& Takahama, T. (1980) Effect of oral adsorbent on animal model of hepatic failure. Jap. J . artif. Organs., 9, 331-333. (in Japanese with English summary). 